\section{TRAINING OF THE FEEBLE-MINDED.}

BY FRANCIS WARNER, M.D., F.R.O.P. LOND., PHYSICIAN TO THE LONDON HOSPITAL.

THE study of the best means of training persons feebleminded but not imbecile, whether children or adults, has attracted much attention of recent years. The subject forms an interesting department of mental science and presents many problems of great importance, some of which bave a bearing on general education in higher as well as in the lower conditions of mental status. Mental processes as they occur in the feeble-minded are not altogether unlike in kind to those which may be observed in well developed brains, but each act is slower and more difficult to control, while the impressions produced are less easily connected or combined for useful action or methods of thought. Since the passing of the Elementary Education (Defective and Epileptic Children) Act, 1899, defective children have been admitted to classes of special instruction under many school ooards, and a few homes have been provided for the maintenance of adult cases. This is not the opportinnity for giving an explanation of the principles of physiology and mental science that are applicable to the culture of feeble. minded brains, but I would urge upon all who are concerned with such cases the necessity of bestowing their powers of observation and thought to the work and devoting their best efforts to the attainment of the ends in view. The elementary methods of training used for imparting mental faculty to feeble-minded children have also been found adaptable to adult cases. Some power of attention must be cultivated; the child may be fidgety, doing nothing he is told to do, wanting to run about, not being easily controlled; the adult is often sullen, apathetic, very slow and inert in all action. In each class the attention is at first most easily cultivated by sight. The pupil must be made to look at things, not only by turning his head but by moving the eyes; this is very necessary in reacoing and in working sums. Let him follow with his eyes your hand as it moves, holding up a penny or a lighted match, always taking care that his eyes are directed towards it and that they follow the movements made. Control over eye movements gives the teacher the power to make the pupil look at, and therefore to see, objects accurately ; he will learn to look at his teacher's mouth when being taught speech, at her hand in finger exercises, at abjects of instruction shown or counted, and at the parts of the drawing on the blackboard. By thus training the eye movements control is obtained over certain brain centres through sight. It is an all-important rule in this elementary training to use one kind of control only at a time, by sight, sound, or touch separately; the different classes of impressions produced may then be connected for the mental process of comparison more easily than when an object is simultaneously seen and handled while its name is pronounced. When, during the course of several weeks of educational effort the pupil has been thus trained he will have made some progress in useful action and have advanced one step towards learning t? read and to write.

The most educative agent acting on the feeble-brained child under training is the teacher-the teacher's body, hands, face, action as seen, and her voice. The pupil who is sufficiently under control to be made to look steadily at his teacher's hand will easily be made to imitate its action, and this may be employed as a means of educating the brain centres that move his hand in producing a series of finger exercises to be employed later in writing and self-helpfulness. Much has been said about training the hand; it should be remembered that it is the pupil's brain we want to educa te by impressions received through the hand or, speaking more accurately, through the muscles that move the hand and the fingers-i.e, by muscular sense. When the hands are held out free with the fingers separated they should be on a level with the shoulders, the elbows being straight, the arms parallel to one another, and the wrist, the palm of the hand, and the fingers all in the same plane without any drooping. This balance of the hand should be aimed at before any finger exercise is attempted and repeated after each lesson. The pupil may

1 A paper read before the National Association for Benefiting the Feeble-minded. then be directed to look at the teacher's hand and to imitate its action as the fingers move one at a time or in com. binations of two or three; such movements may be either in bending or may be made laterally, the latter being more difficult of exact repetition; exercises in turning the palm upwards and downwards should also be practised. In these imitation movements impressions are made on the brain centres of the pupil by sight. Other exercises may be employed in which passive movements of the child's body control his action. Such exercises may be called "transfer movements." While the pupil's hands are held out take hold of one and explain to him that he is to move the fingers of the otber hand in the same way as you move those of the hand which you hold. Thus you control the brain action of the free hand and can observe the accuracy of the movements produced in it. These exercises are very educative.

We want to get full command over the pupil's brain by every means at our disposal. This applies not only to producing activity with movement, and as a result " something done," but also to resting, relaxing, and standing at ease when temporarily unoccupied. Further, in most useful actions you want just some movement made, not movement all over the body. In writing and in sewing the fingers should do the work without stiffness or tension of the muscles in the arms. A feeble-brained child when told to hold out his hands often tends to keep them forward after others have dropped theirs; this is a waste of power. The limbs are often found to be stiff and consequently awkward in action, while the finer movements of the fingers are difficult to obtain. When you take hold of a child's arm, telling him to leave it alone and to let it fall, if his muscles relax you feel the full weight of the limb on your hand. If you attract his attention to something else his muscles are more likely to relax; conversely, if you can bring about this relaxation, which is a change in the action of his brain, you may be better able to get his attention to other matters. This is, I think, specially important in epileptic cases ; the power of voluntary rest is as important as volition in activity. Seat a boy on the table with the leg and knee hanging free, tell him to leave it loose, attracting his attention the while, if the foot swings freely you have succeeded in relaxing his muscles and in securing his attention.

When these methods of elementary training have been practised and some proficiency obtained in such exercises as have been described attempts may be made to produce brain action of the kind necessary in the mental process of comparison and judgment. The teacher should proceed stage by stage in preparing the pupil's brain to acquire power for reading and writing and a knowledge of numbers, the use of money, its comparative value in purchasing articles, \&c With this object in view we must largely train by exercise of the muscular sense or feeling of movement and the degree of strain felt, as by weights placed on the open hand. Let the pupil feel the size of objects on the table with his fingersthus he feels size only, not the weight; again, with the hand open he may feel weights placed on the fingers-then he feels weight only. Subsequently he will learn to compare coins as to size and weight and learn later that the florin buys twice as much tea as the shilling, the value being proportional to the weight. Much good education may be imparted by extending such methods even before the pupil understands much verbal teaching. Lessons in matching coloured papers; experience in feeling two vessels containing hot water of different temperatures; discrimination between loud and soft sounds, all convey impressions to the pupil's brain that may afterwards become classed and associated in acts of comparison and judgment.

The previous training in imitation of action seen in the teacher prepares the pupil to learn to write and to speak with good pronunciation. Having learned to move his hand as he sees his teacher do, writing on the blackboard may be taught. The boy looking at the teacher's hand while writing with chalk as be stands beside her, moves his own in imitation, and so learns to make the letters, while the action necessary in pronouncing vowels and consonants is imitated from her lips. Breathing exercises and care to increase the child's vocabulary do much to aid proper speaking. Knowledge of time as seen by the clock and a practical acquaintance with the time occupied by dressing, meals, walks, \&c., should be taught. All details in self-helpfulness should be subjects of school-room teaching where each item may rece ve separate attention. These young people 
eneed constant supervision throughout the day and are to most happy when employed with drill, marching, drawing, modelling, games, and walks ; each occupation finds an appropriate place in their education as well as the par. ticular items in elementary training that have been described. The teaeher engaged with this interesting class of pupils will need to make a constant study of each child so that observation may lead to inference of the impressions received by the pupil and their mode of interaction in mental processes. It is sery desirable that teachers for these children should have special instruction how to observe a child; what to look at, what to look for, and as to the means of describing what is seen and of drawing inferences as to mental status and action. In every charitable home for the care of the feeble.minded, whether intended for children or adults, some portion of the morning of each day should, I think, be devoted to definite mental training and some member of the staff should receive instruction as to the elementary training of the inmates.

Prince of Wales-terrace, $\mathrm{W}$.

\section{TWO CASES OF}

HYPERTROPHIED BREASTS IN THE MALE (GYN尔COMASTIA).

BY A. WEBB JONES, F.R.C.S. ENG.,

SURGEON TO WOMEN AT THE GOVERNMENT HOSPITAL, ALEXANDRIA; AND

J. B. CHRISTOPHERSON, M.A., M.D. CANTAB., F.R.C.S. ENG.,

ISURGEON TO THE OMDURMAN GIVIL HOSPITAL, KHARTOUM.

ON account of the rarity of the above-mentioned condition we have thought the following two cases worthy of record.

OASE 1.-The patient was a Sudanese boy, aged about 14 years. Both breasts were well developed, firm and elastic to the touch, and in fact presented all the characteristics of the female breast in an individual of the same age (see Fig. 1). Generally the boy was well developed.

FIG. 1.

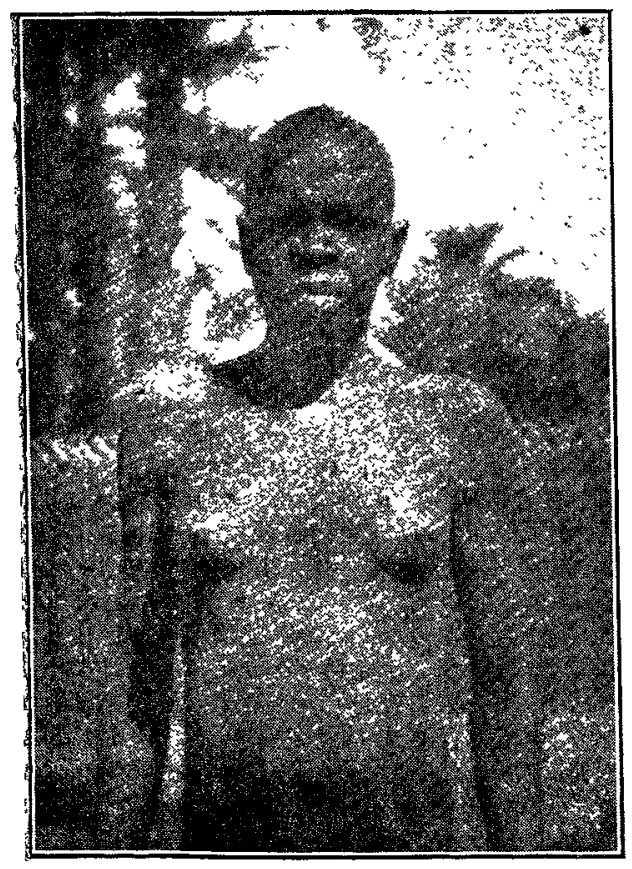

Showing bypertrophy of the breasts in a boy aged 14 years.

To escape from the chaff of his comrades he was forced constantly to wear a shirt when at work and this indeed was the reason that led him to seek surgical advice. He was admitted into Dongola Oivil Hospital where both breasts were removed by a curved incision at the lower periphery, leaving the nipples intact. Microscopical examination (kindly made for us by Mr. S. G. Shattock) showed the following condition: "The increase in size is due mainly to dense (though well-ảeveloped) fibrous tissue. But it should be classed as hypertrophy and not elephantiasis or fibrosis, since the number of acini is not less than in the normal female breast. The epithelium is proliferating but there is only here and there evidence of interstitial inflam. mation. One must regard the breast as hypertrophied and, in addition, the seat of a parenchymatous mastitis."

CASE 2. - The patient was a Fertit boy living at Omdurman, admitted to hospital in February, 1903, presenting a large raw area in the left mammary region and several clean-cut semicircular gashes above the right breast. He had completely amputated his own left breast with the aid of a razor and was proceeding with the same operation on the right side when either he fainted or his courage failed. The right breast, though small, was distinctly feminine in appearance. Like the virgin breast, its outline was clearly marked off from the subcutaneous fat or the pectoral muscle beneath; the outline was slightly concave above and convex below so that the nipple was directed a little upwards and outwards. According to the lad's statement the breasts were increasing in size and he had mutilated himself on account of his resemblance to a woman. Generally he was well developed, as the accompanying reproduction of a photrgraph (Fig. 2)

Fig. 2.

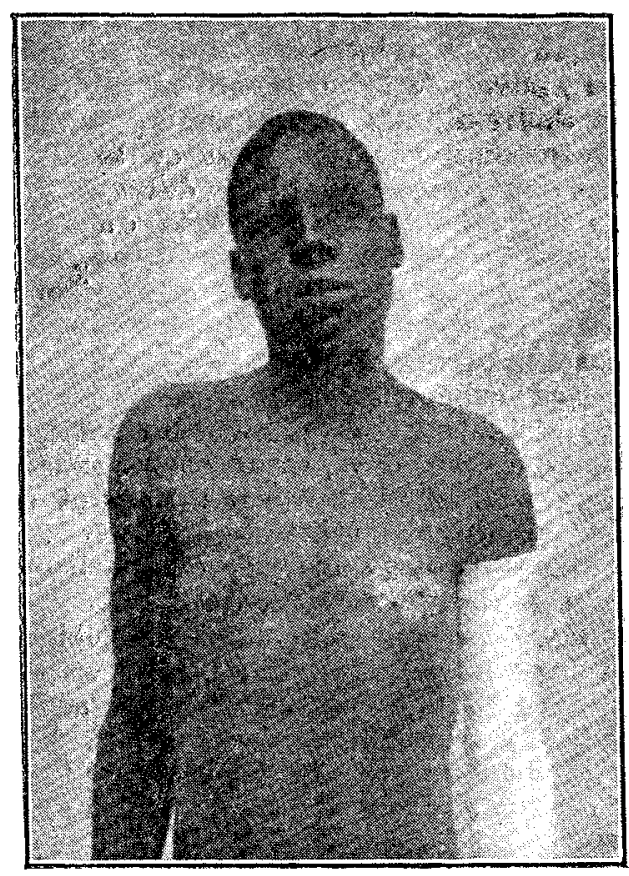

Showing bypertrophy of the breast in a boy.

shows, and was of a muscular, manly type. The left breast was skin-grafted and the right was removed through the incision made by the boy, the nipple being left intact. 1t enucleated easily except at the nipple. In size it resembled a small Tangerine orange cut through the equator and presented all the naked-eye characters of a female breast.

Although this was not so marked a case of gy næcomastia as in Case 1 , it completes the story and emphasises the rarity of the condition in the Anglo-Egyptian Sadan. Men are often seen who have prominent pendulous chest development, either on account of the size of the pectoral muscles-this especially in Sudanese colporteurs-or on account of a local deposit of fat in the mammary regicn. Such men may call forth the remark that they have breasts like a woman but the breasts are cistinct from the condition described above and contain no adenomatous tissue.

It is to be remarked that both lads came from the same tribe (the Firtitawi). Rumour says that the condition is not uncommon amongst them and $\operatorname{Sir} H$. Johnstone says that enlarged breasts in the male are not uncommon amongst the negroes of Central Africa. However this may be, both boys were much ashamed of their appearance, a jact which makes it quite clear that, at any rate in the districts in which they were living (Merowi and Omdurman), hypertrophy must be extremely rare. The Firtitawi are a very primitive people and this, so far as it goes, supports Williams's theory that the hypertrophy is a reversion to the condition prevalent when the males aided the females in suckling their young. 